\title{
The Clinical Course of Takotsubo Syndrome Diagnosed According to the InterTAK Criteria
}

Nelson Henrique Fantin Fundão, ${ }^{1 \odot}$ Henrique Barbosa Ribeiro, ${ }^{1,2}{ }^{\circledR}$ Carlos de Magalhães Campos, ${ }^{1,3}{ }^{\circledR}$ Vinicius Bocchino Seleme, ${ }^{1 \oplus}$ Alexandre de Matos Soeiro, ${ }^{1 \oplus}$ Marcelo Luiz Campos Vieira, ${ }^{1,3 \oplus}$ Wilson Mathias $\mathrm{Jr},{ }^{1 \oplus}$ Ludhmilla Abraão Hajjar, ${ }^{1,2}$ Expedito E. Ribeiro, ${ }^{1,2}$ Roberto Kalil Filho ${ }^{1,2} @$

Universidade de São Paulo - Instituto do Coração, 'São Paulo, SP - Brazil.

Hospital Sírio-Libanês, São Paulo, ${ }^{2}$ SP - Brazil.

Hospital Israelita Albert Einstein, ${ }^{3}$ São Paulo, SP - Brazil.

\section{Abstract}

Background: There has been an increase in the number of cases of Takotsubo syndrome (TTS) and of scientific publications on the theme over the last years. However, little is known about the status of this disease in Brazilian hospitals.

Objective: To assess mortality and major adverse cardiovascular events (MACE) during hospitalization and follow-up of TTS patients seen in a tertiary hospital in Brazil.

Methods: This was a retrospective, observational study on 48 patients. Clinical data, signs and symptoms, complementary tests, MACE and all-cause mortality were assessed on admission and during follow-up. Kaplan-Meier curves were used for analysis of all-cause mortality and risk for MACE at median follow-up. The $95 \%$ confidence interval was also calculated for a significance level of $5 \%$.

Results: Mean age of patients was 71 years ( $\mathrm{SD} \pm 13$ years), and most patients were women ( $\mathrm{n}=41 ; 85.4 \%)$. During hospitalization, four patients ( $8.3 \%$ ) died and five (10.4\%) developed MACE. At median follow-up of 354.5 days (IQR of 81.5-896.5 days), the risk of all-cause mortality and MACE was $11.1 \%$ ( $95 \% \mathrm{CI}=1.8-20.3 \%)$ and $12.7 \%(95 \% \mathrm{CI}=3.3-22.3 \%)$, respectively.

Conclusion: TTS was associated with high morbidity and mortality rates in a tertiary hospital in Brazil, which were comparable to those observed in acute coronary syndrome. Therefore, the severity of TTS should not be underestimated, and new therapeutic strategies are required. (Int J Cardiovasc Sci. 2020; 33(6):637-647)

Keywords: Acute Coronary Syndrome; Takotsubo Cardiomyopathy; Heart Failure; Shock, Cardiogenic; Ventricular Dysfunction.

\section{Introduction}

The term "Takotsubo syndrome" (TTS) emerged in the medical literature in the 1990s, in a Japanese book of medicine, to describe a syndrome of symptoms and electrocardiographic changes suggestive of acute myocardial infarction (AMI), but coronary arteries without significant obstructive lesions. ${ }^{1,2}$ The name "takotsubo" comes from the similarity between the cardiac ventriculography in these patients and an old octopus trap used in Japan (in Japanese, "tako" means octopus and "tsubo" means pot/vase). ${ }^{1,3}$
The pathophysiology of TTS is essentially related to an exacerbated activation of sympathetic autonomic nervous system. However, the mechanism by which catecholamine excess triggers myocardial stunning, with a variety of motion segment dysfunction patterns that characterize this syndrome (dysfunctional apical mid-ventricular, basal or focal segments) is unknown. ${ }^{1}$

Despite the significant increase in the number of patients diagnosed with TTS, ${ }^{4}$ and publication of international studies on the theme over the last years, ${ }^{5}$ little is known about current reality of the disease in Brazil.

Mailing Address: Carlos de Magalhães Campos

Av. Dr. Enéas Carvalho de Aguiar, 44. Postal code: 05403-900, Cerqueira César, São Paulo, SP - Brazil

E-mail: carlosacampos1@gmail.com 
The aim of this registry was to assess mortality and major adverse cardiac events (MACE) - composed of stroke/transient ischemic accident (TIA), myocardial revascularization and cardiac mortality - in-hospital and during follow-up, in patients diagnosed with TTS according to InterTAK diagnostic criteria.

\section{Methods}

Since the first description of TTS, no widely accepted criteria for the diagnosis of TTS have been established. The most used criteria are the Mayo Clinic criteria, modified in 2008. ${ }^{6}$ According to these criteria, although the presence of coronary obstructive lesion does not rule out the diagnosis of TTS, this information is not clearly defined and described as very rare. ${ }^{7}$ However, other publications have evidenced that up to $10-29 \%$ of the patients diagnosed with TTS have concomitant obstructive coronary disease..$^{8-10}$ Therefore, in attempt to define a new consensus and based on the last available data, a new set of diagnostic criteria (InterTAK criteria) was proposed by experts in TTS in 2018 (Figure 1). ${ }^{1}$

\section{Study Population}

This was a retrospective observational study, approved by the institutional ethics committee

International Takotsubo Diagnostic Criteria

(InterTAK Diagnostic Criteria)

1. Patients with transient ${ }^{a}$ left ventricular dysfunction (hypokinesia, akinesia, or dyskinesia) presenting as apical ballooning or other left ventricular segmental (midventricular, basal, or focal) wall motion abnormalities. Right ventricular involvement can be present. Besides these regional wall motion patterns, transitions between all types can exist. The regional wall motion abnormality usually extends beyond a single epicardial vascular distribution; however, rare cases can exist where the regional wall motion abnormality is present in the subtended myocardial territory of a single coronary artery (focal TTS). ${ }^{b}$

2. An emotional, physical, or combined trigger can precede the Takotsubo syndrome event, but this is not obligatory.

3. Neurologic disorders (e.g. subarachnoid haemorrhage, stroke/transient ischaemic attack, or seizures) as well as pheochromocytoma may serve as triggers for takotsubo syndrome.

4. New ECG abnormalities are present (ST-segment elevation, ST-segment depression, T-wave inversion, and QTc prolongation); however, rare cases exist without any ECG changes.

5. Levels of cardiac biomarkers (troponin and creatine kinase) are moderately elevated in most cases; significant elevation of brain natriuretic peptide is common.

6. Significant coronary artery disease is not a contradiction in takotsubo syndrome.

7. Patients have no evidence of infectious myocarditis. ${ }^{b}$

8. Postmenopausal women are predominantly affected.

a Ventricular contraction abnormalities may remain for a prolonged period of time or documentation of recovery may not be possible. For example, death before evidence of recovery is captured.

${ }^{\mathrm{b}}$ Cardiac magnetic resonance imaging is recommended to exclude infectious myocarditis and diagnosis confirmation of Takotsubo syndrome. ${ }^{1}$ 
(approval number 3.279.964), conducted following best practices in research.

Electronic data of hospital admissions occurring between January 01, 2013 and December 31, 2018 (six year-period; 75,284 admissions) in the Heart Institute of the University of Sao Paulo (InCor HCFMUSP) were analyzed. The following terms were searched in the electronic charts: "Takotsubo syndrome", "Takotsubo cardiomyopathy", "Broken Heart Syndrome", "Stress-Induced Cardiomyopathy" and "Adrenergic Cardiomyopathy".

One hundred and one patients older than 18 years of age were found in the search. Based on the InterTAK diagnostic criteria, TTS was excluded in 53 individuals, and 48 patients were included in the study. Forty-four patients met all diagnostic criteria (including one patient who developed TTS in the postoperative period of cardiac surgery), and four patients, despite fulfilling all the interTAK criteria in the postoperative of cardiac surgery, did not have an anatomical study of coronary artery for the event (all patients underwent preoperative cineangiography, with no evidence of coronary lesions) (Figure 2).
The InterTAK criteria, similar to previous diagnostic criteria for TTS, do not mention the occurrence of the syndrome in the postoperative period of cardiac surgery, ${ }^{11}$ i.e., do not confirm or exclude the diagnosis of TTS such case. However, due to the increasing number of TTS following cardiac surgery reported in the literature, ${ }^{12-15}$ we decided to include these patients in the analysis.

\section{Data Collection and Variables Analyzed}

Data collection was made by review of electronic medical records of the 48 patients selected. When follow-up data after discharge were not available, patients were contacted by telephone to obtain information about new MACE and mortality.

At admission and during hospitalization, information on previous clinical data, signs and symptoms, complementary tests, MACE, all-cause mortality, length of hospital stay, signs of heart failure, signs of renal failure and new arrhythmias was assessed. In the out-of-hospital follow-up, data on MACE, overall mortality and left ventricular

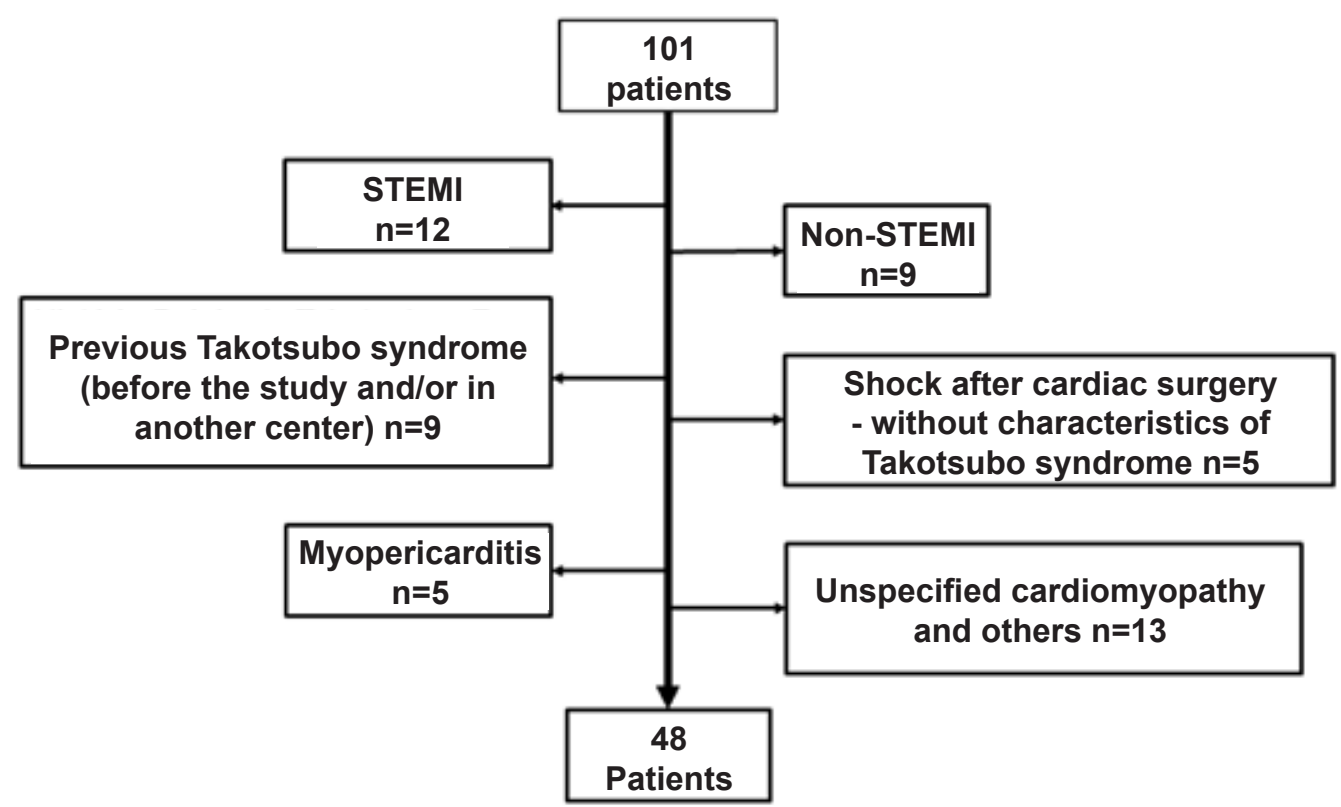

Figure 2 - Study population 
ejection fraction values, determined by transthoracic echocardiography, were assessed.

Racial group classifications (white, black or "pardo") were collected from electronic medical records, which are usually filled with self-declared race.

The diagnosis of acute renal failure (ARF) was made based on the 'injury' definition of RIFLE criteria ${ }^{16}$, which consider a two-fold increase of serum creatinine from baseline or a decrease of at least $50 \%$ in estimated glomerular filtration rate. RIFLE criteria define at least three grades of severity of ARF - 'risk', 'injury' and 'failure' - we adopted the 'injury' definition criteria for a balance between sensitivity and specificity for diagnosis of ARF.

\section{Statistical Analysis}

All variables were tested for normality using the Shapiro-Francia test. For continuous variables with normal distribution, mean and standard deviation were calculated, and for variables without a normal distribution, median and interquartile range (IQR) were determined. Categorical variables were expressed as absolute numbers and percentages of total population. Data analysis was performed using the IBM SPSS Statistics software package, version 25.0. The KaplanMeier survival curves were analyzed using MEDCALC ${ }^{\circledR}$, version 19.

Kaplan-Meier survival curves were used to estimate the risk of all-cause mortality, and the risk of MACE was defined in the median follow-up time. A 95\% confidence interval $(95 \% \mathrm{CI})$ was calculated with a significance level of $5 \%$.

\section{Results}

Table 1 describes the clinical features of patients at admission. Most patients were women (85.4\%); $70.8 \%$ had systemic arterial hypertension and $14.6 \%$ were diabetic.

Most of the cases (75\%) manifested with chest pain on presentation, mainly chest pain with anginal characteristics $-47.9 \%$ of the study population (Table 2 ). Regarding the triggering factor, there is a preponderance of physical causes (such as bronchospasm, neoplasia under treatment, surgeries and other concomitant diseases), corresponding to $47.9 \%$ of individuals included in the registry.

Regarding complementary tests (Table 2), what draws attention is that almost all patients $(97.9 \%)$ had

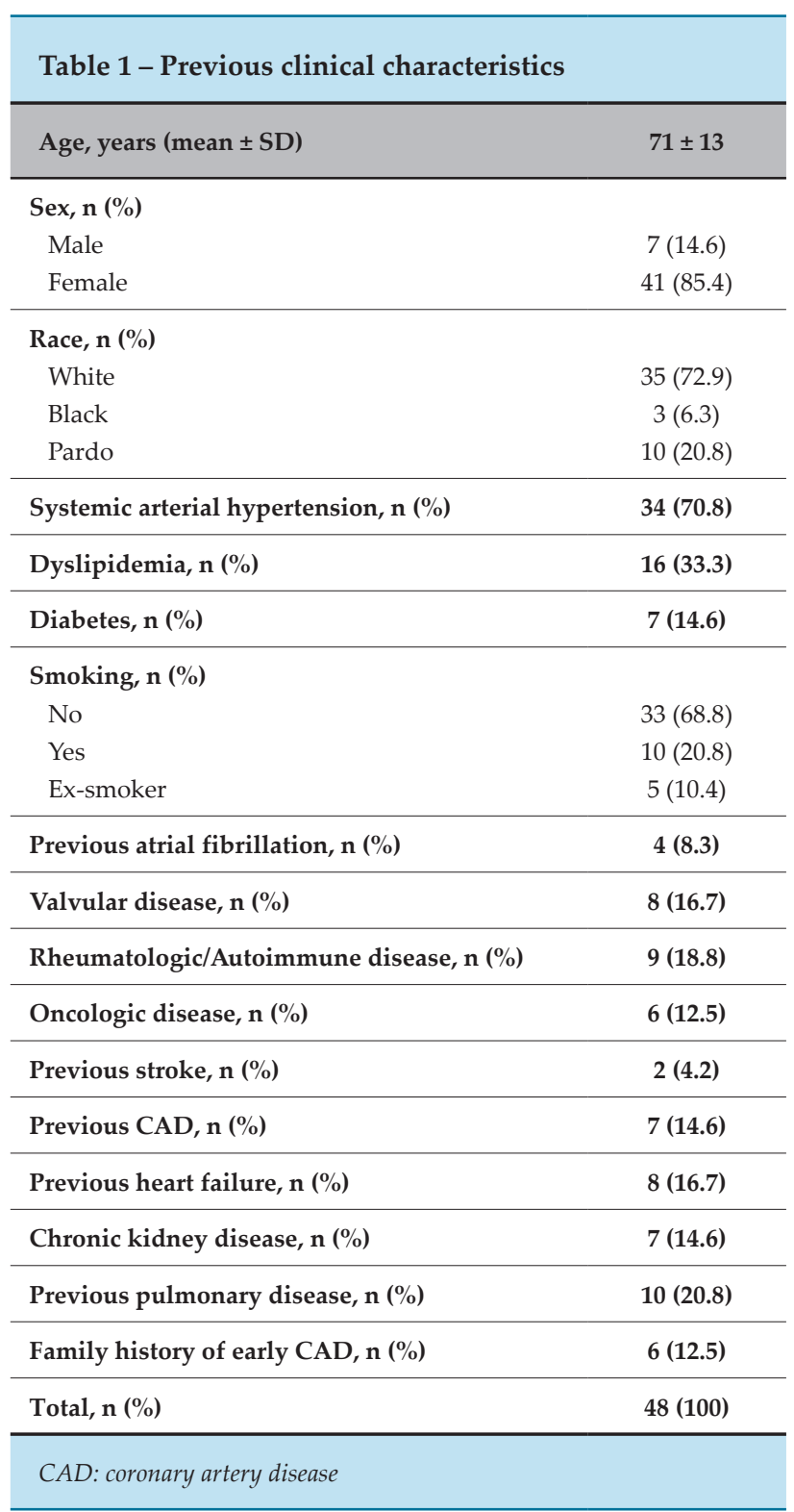

electrocardiographic changes, mainly T-wave inversion ( $47.9 \%$ of the cases). Cineangiography was available during the TTS event for most patients (91.7\%), except for four patients $(8.3 \%)$ who underwent valve replacement surgery and had undergone the test prior to the surgery, and had no evidence of coronary obstructive lesions. In most of TTS patients, there was involvement of the left ventricular apex $(87.5 \%)$, which is in agreement with the typical presentation of the disease, where apical dysfunction is predominant.

In addition, $10.4 \%$ of patients had left ventricular outflow tract obstruction, which increases the severity of the disease due to the increase in the incidence of hypotension and cardiogenic shock..$^{17,18}$ 


\begin{tabular}{|c|c|}
\hline \multicolumn{2}{|l|}{ Clinical manifestations } \\
\hline Chest pain, $\mathrm{n}(\%)$ & $36(75)$ \\
\hline Atypical pain & $23(47.9)$ \\
\hline Typical pain & $13(27.1)$ \\
\hline Dyspnea, n (\%) & $10(20.8)$ \\
\hline Syncope, n (\%) & $2(4.2)$ \\
\hline \multicolumn{2}{|l|}{ Triggering factors, $\mathrm{n}(\%)$} \\
\hline Physical triggers & $23(47.9)$ \\
\hline Psychological triggers & $15(31.3)$ \\
\hline Not reported & $10(20.8)$ \\
\hline Heart rate, Mean \pm SD & $82.16 \pm 17.7$ \\
\hline Systolic blood pressure, median (IQR) & $121.5(110-139.2)$ \\
\hline \multicolumn{2}{|l|}{ Complementary tests } \\
\hline \multicolumn{2}{|l|}{ Electrocardiographic changes, $\mathrm{n}(\%)$} \\
\hline ST-elevation & $18(37.5)$ \\
\hline Anterior wall & $13(27.1)$ \\
\hline Lateral wall & $9(18.8)$ \\
\hline Inferior wall & $4(8.3)$ \\
\hline ST-depression & $4(8.3)$ \\
\hline T-wave inversion & $23(47.9)$ \\
\hline Nonspecific changes & $5(10.4)$ \\
\hline Normal & $1(2.1)$ \\
\hline Cineangiography during the event, n (\%) & $44(91.7)$ \\
\hline Coronary obstructive lesion $\geq 50 \%$ & $13(27)$ \\
\hline \multicolumn{2}{|l|}{ Type of Takotsubo cardiomyopathy, $n$ (\%) } \\
\hline Apical & $42(87.5)$ \\
\hline Mid-ventricular & $2(4.2)$ \\
\hline Basal & 0 \\
\hline Focal & $4(8.3)$ \\
\hline \multirow{8}{*}{$\begin{array}{l}\text { Echocardiography during the event, } \mathrm{n}(\%) \\
\mathrm{LVEF}(\%) \text {, mean } \pm \mathrm{SD} \\
\text { Left atrial diameter }(\mathrm{mm}) \text {, mean } \pm \mathrm{SD} \\
\mathrm{LV} \text { diastolic diameter }(\mathrm{mm}) \text {, mean } \pm \mathrm{SD} \text { Left ventricular systolic diameter }(\mathrm{mm}) \text {, mean } \pm \mathrm{SD} \\
\text { Pericardial effusion, } \mathrm{n}(\%) \\
\text { Moderate/severe mitral insufficiency, } \mathrm{n}(\%)\end{array}$} & $41(85.4)$ \\
\hline & $42.73 \pm 9.3$ \\
\hline & $37.5 \pm 5.2$ \\
\hline & $47.4 \pm 4.3$ \\
\hline & $32.1 \pm 4.8$ \\
\hline & $4(8.3)$ \\
\hline & $5(10.4)$ \\
\hline & $5(10.4)$ \\
\hline Cardiac nuclear magnetic resonance, n (\%) & $18(37.5)$ \\
\hline Involvement of the right ventricle at Echo or NMRi, n (\%) & $2(4.2)$ \\
\hline LV thrombus on Echo or NMRi, n (\%) & 0 \\
\hline \multicolumn{2}{|l|}{ High-sensitivity troponin $I^{*}(\mathrm{ng} / \mathrm{mL})$, Median (IQR) } \\
\hline Baseline & $3.41(1.90-5.78)$ \\
\hline Peak & $5.38(3.45-17.44)$ \\
\hline \multicolumn{2}{|l|}{ CK-MB Masst (ng/mL), Median (IQR) } \\
\hline Baseline & $11.3(6.03-20.05)$ \\
\hline Peak & $16.6(12.6-26.85)$ \\
\hline BNP $\ddagger(\mathrm{pg} / \mathrm{mL})$, Median (IQR) & $1788(501.5-2478.5)$ \\
\hline \multicolumn{2}{|l|}{ Creatinine (mg/dL), Median (IQR) } \\
\hline Baseline & $0.98(0.77-1.37)$ \\
\hline Peak & $1.27(0.89-2.26)$ \\
\hline \multicolumn{2}{|c|}{$\begin{array}{l}\text { Reference values: }{ }^{*} \text { Troponin } I \leq 0.04 \mathrm{ng} / \mathrm{mL} /+C K-M B \text { Mass } \leq 4.4 \mathrm{ng} / \mathrm{mL} / \mp B N P<100 \mathrm{pg} / \mathrm{mL} \text {. BNP levels were available for } 13(27 \%) \text { of the } 48 \text { patients } \\
\text { included in the study. BNP: brain natriuretic peptide; CKMB: creatine phosphokinase-MB; SD: standard deviation; LVEF: left ventricular ejection } \\
\text { fraction; Echo: echocardiogram; IQR: interquartile range; NMRi: nuclear magnetic resonance imaging; LV: left ventricular }\end{array}$} \\
\hline
\end{tabular}




\section{Left Ventricular Function}

Figure 3A shows left ventricular circumferential dysfunction, and Figure 3B displays a comparative analysis between left ventricular function on admission and on echocardiographic follow-up (in-hospital or our-of-hospital) $(n=30)$. Almost all patients (96.6\%) showed recovery of the LVEF, which makes clear the temporary nature of ventricular dysfunction. In this analysis, only one patient did not show improvement of LVEF, which may be explained by the short time from diagnosis to transthoracic echocardiography (four days), i.e., probably, there was no enough time for recovery of the left ventricular function. This patient progressed to death.

\section{Clinical Course}

In-hospital outcomes and medications are described in Table 3. A significant proportion of patients (41.7\%) developed heart failure during hospitalization, which is the main complication of TTS. ${ }^{19}$ High in-hospital mortality $(8.3 \%)$ and MACE rates (10.4\%) were also observed.

Median follow-up was 354.5 days (IQR $=81.5-$ 896.5 days), with an all-cause mortality of $11.1 \%$ (95\% CI: $1.8-20.3 \%$ ), and prevalence of MACE of $12.7 \%$ (95\%
CI> 3.3-22.3\%) (Figure 4). Interestingly, all MACE occurred during the first three months of follow-up after the diagnosis.

\section{Discussion}

The main findings of this study were: (1) the use of the InterTAK diagnostic criteria helped in the establishment of the correct diagnosis of TTC in $47.5 \%$ of the 101 patients enrolled in the study; (2) there is a considerable number of TTS patients with concomitant coronary artery disease (CAD); (3) a normalization of ventricular function was detected by echocardiographic follow-up in almost all patients; and (4) there was a high prevalence of clinical events in short-term follow-up.

With respect to diagnosis, the TTS diagnosis was initially considered for 101 patients and, after application of the InterTAK criteria, the diagnosis was confirmed in 48 patients $(47.5 \%)$. This finding reinforces that a correct diagnosis of STT is not easy and requires a systematic approach to the diagnostic criteria, which have evolved over the years.

Some years ago, little attention was paid to the possibility of a TTS patient having important coronary
A

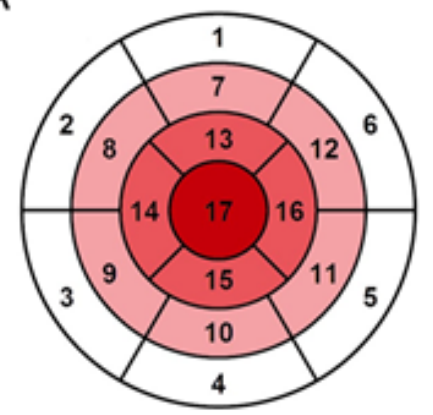

Segments: 1 . basal anterior /2. anteroseptal/3. basal inferoseptal/4.basal inferior/5.basal inferolateral/6.basal anterolateral $/ 7 . \mathrm{mid}$ anterior/8. mid anteroseptal/9. mid inferoseptal/10.mid inferior/11.mid inferolateral/12.mid anterolateral/13.apical anterior/14.apical septal/15.apical inferior/16.apical lateral/17.apex
B
80

70

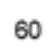

50

40

30

20

10

0
Left ventricular ejection fraction (\%)

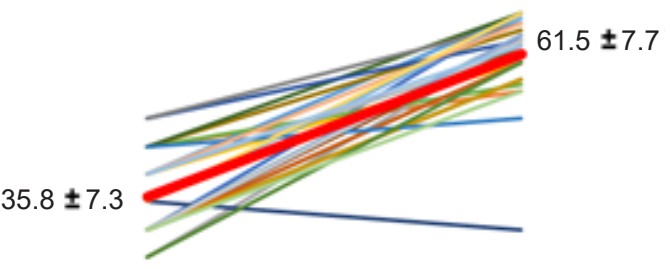

67.5 (22.3-192.8) days

Admission

Follow-up 
Table 3 - Hospitalization data and medications

$\begin{aligned} & \text { Length of hospital stay, days, median } \\ & \text { (IQR) }\end{aligned}$
Acute renal failure, n (\%)
Acute decompensation of CKD, n (\%)
All-cause in-hospital mortality, n (\%)
In-hospital MACE, n (\%)
Cardiac mortality, n (\%)
AMI, n (\%)
Revascularization, n (\%)
TIA/stroke, n (\%)

Non-cardiac mortality, n (\%)

Mechanical ventilation requirement, $\mathbf{n}$ (\%)

Heart failure, $\mathbf{n}(\%)$
Killip classification, $\mathbf{n}(\%)$
1
2
3
4

New arrhythmia, $\mathbf{n}(\%)$

$\mathrm{VF} / \mathrm{TV}, \mathrm{n}(\%)$

Atrial fibrillation, $\mathrm{n}(\%)$

Medications administered

Acetylsalicylic acid, n (\%)

$22(45.8)$

Clopidogrel, n (\%)

$10(20.8)$

Beta blocker, n (\%)

28 (58.3)

Statin, $\mathbf{n}(\%)$

31 (64.6)

ACEI, $\mathbf{n}(\%)$

$30(62.5)$

ARBs, n (\%)

$3(6.3)$

Spironolactone, $\mathbf{n}(\%)$

CKD: chronic kidney disease; MACE: major adverse cardiac events AMI: acute myocardial infarction; TIA: transient ischemic accident (TIA), VF: ventricular fibrillation; AF: atrial fibrillation; ACEI: angiotensin converting enzyme inhibitors; $A R B s$ : angiotensin receptor blockers; IQR: interquartile range

obstructive disease, which has been corrected by the new criteria proposed (Figure 1). Usually, the association between TTS and CAD is not a causeeffect relationship. Despite the rare cases of TTS patients in whom acute coronary syndrome was the cause of TTS, ${ }^{20-22}$ it is believed that, in most cases, the coronary obstructive lesions found in TTS patients are complementary test findings, since the main population affected by the syndrome (postmenopausal women) is also a group with a significant prevalence of CAD. ${ }^{23}$ In the present study, in line with the complementary tests' results (Table 2), there was a significant prevalence of patients $(27 \%$ of the study population) with coronary obstructive lesion $\geq 50 \%$ of vessel lumen diameter. This is in agreement with more recent literature data, showing a prevalence of $10-29 \%$ of TTS patients with concomitant obstructive coronary disease e-10 $^{8}$

Another important issue is the development of electrocardiographic abonrmalities, circumferential dysfunction of ventricular contraction at transthoracic echocardiography, and clinical signs/symptoms (precordial pain and/or hypotension/circulatory shock) in the immediate post-operative period after cardiac surgery. These are possible manifestations of TTS, probably caused by extracorporeal circulation and surgical trauma. In the present study, these patients represented $10.4 \%$ of the cases. For the next diagnostic criteria updates, the inclusion of cardiac surgery as trigger for TTS should be considered.

The transient character of left ventricular dysfunction in TTS patients has been consolidated in previous studies and is one of the disease characteristics included in the diagnostic criteria for TTS. 1,6,24-26 This feature was corroborated by our findings of the analysis of ventricular function (Figure $3 \mathrm{~B})$, which supports the correct diagnosis of TTS in our study group.

Regarding morbidity and mortality of TTS, the mortality rate in previous series was lower - in-hospital mortality of $1-2 \%,{ }^{27-28}$ - which generated an erroneous idea of the benign character of the disease. More recent studies, including a greater number of patients and longer follow-up, have shown much higher mortality rates (in-hospital mortality 4-5\%), compatible with the mortality rate of acute coronary syndrome treated according to current recommendations. ${ }^{8,29-32}$

The largest registry of TTS available, including 1,750 patients, reported an in-hospital mortality rate of $4.1 \%$ and overall mortality of up to $5.6 \%$ per patient/ year and MACE of $9.9 \%$ during follow-up. ${ }^{8}$ Similar mortality and MACE rates were found in our study, reinforcing the severity of the disease.

Another finding that deserves attention is the fact that the events occurred within three months after the diagnosis of TTS. Since ventricular dysfunction 
A All-cause mortality

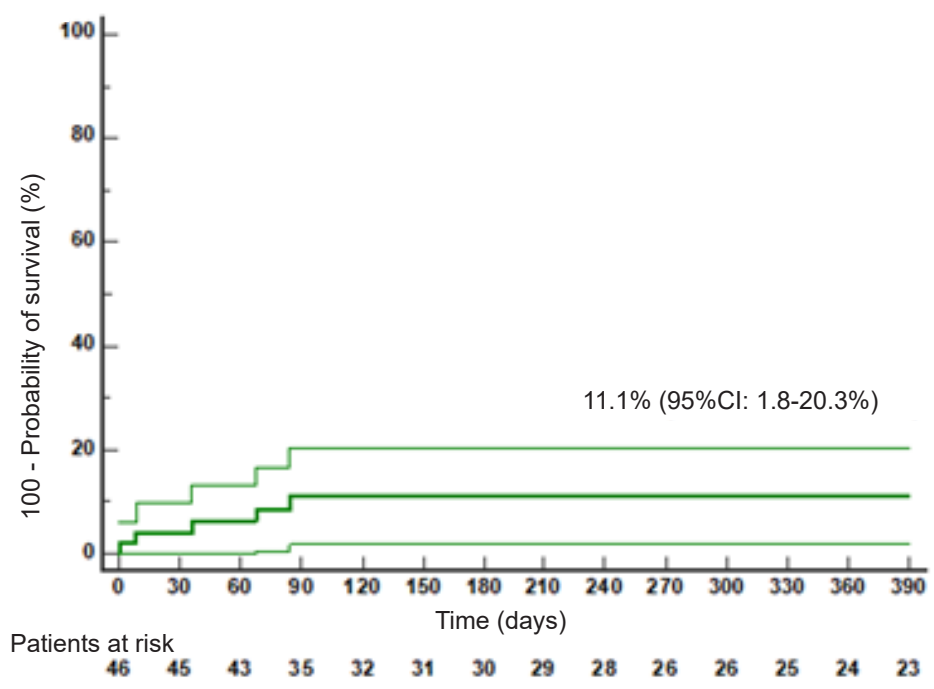

B Major adverse cardiovascular events

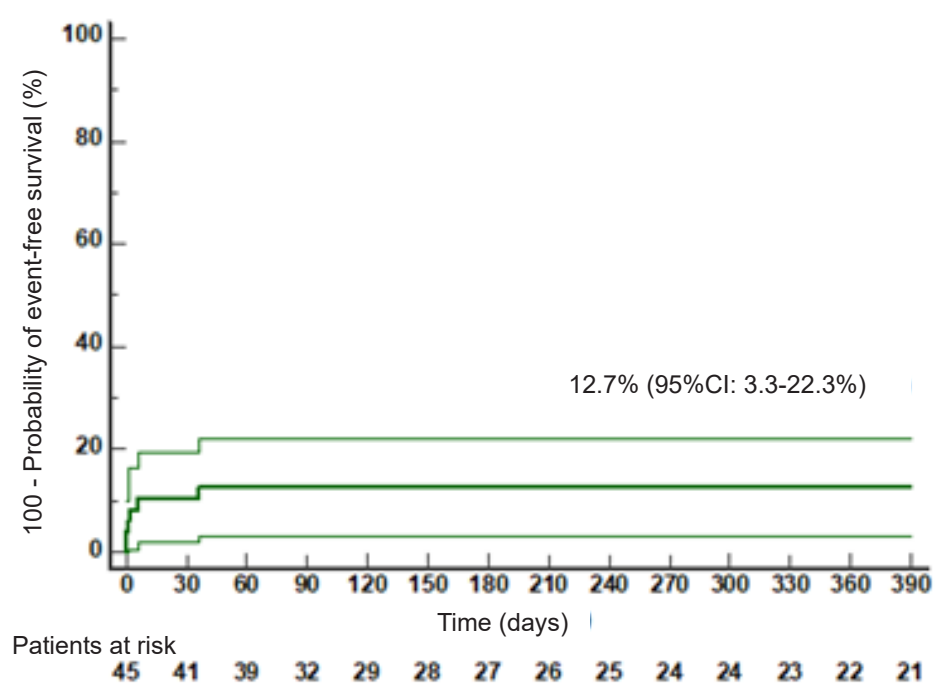

Figure 4 - Kaplan-Meier curves of overall mortality (A) and major adverse cardiovascular events after the diagnosis of Takotsubo syndrome, including both in-hospital and post-discharge events thin lines represent the $95 \%$ confidence interval

is potentially reversible in TTS, we may infer that morbidity and mortality of the disease are concentrated in the first months after the event and, if survives the acute phase, with LVEF recovery, the patient will have an excellent prognosis. However, studies with a larger number of patients and longer follow-up have shown that TTS morbidity and mortality are not limited to the first months after diagnosis, and that MACE may occur for years following the first event, at a rate higher than in general population and similar to CAD patients. ${ }^{8,29}$,
${ }^{33}$ The different results obtained in our study may be due to the relatively small number of patients $(n=48)$ and shorter follow-up, of approximately one year.

The reasons why patients with diagnosis of TTS have higher morbidity and mortality compared with the general population and similar to CAD patients, even in acute phase, are not fully understood. First, it was thought that the fact that some of TTS patients also have CAD could have caused this bias. This was explored by Tornvall et al., ${ }^{29}$ who compared a group 
of patients with TTS and without CAD with further two groups: (a) controls without CAD and TTS; and (b) patients with CAD without TTS. The results were similar to those previously obtained - mortality rate in TTS patients was higher than in controls and similar to the CAD group. Thus, the hypothesis that the concomitance of CAD and TTS would cause higher morbidity and mortality (as compared to healthy controls) became less likely.

Another hypothesis for the high mortality rates after acute phase in TTS patents was based on a populationbased study that reported that TTS patients have more comorbidities than patients with previous $\mathrm{CAD}$, including higher rates of past history of stroke/ transient ischemic attack, drug abuse, psychiatric disorder, oncologic disease, chronic liver disease and sepsis. ${ }^{34}$ Therefore, TTS may be seen as a disorder that often affects already ill patients, with higher morbidity and mortality than the general population.

The treatment of TTS is controversial, and based on clinical experience and experts consensus (level of evidence $\mathrm{C}$ ), since there are no prospective, randomized clinical trials evaluating therapeutic approaches of these patients. ${ }^{19}$ Figure 5 summarizes the main recommendations for treatment of the TTS today. In the present registry, most patients received heart failure medications during hospitalization and after discharge, including beta-blockers (58.3\%) and angiotensin converting enzyme inhibitors $(62.5 \%)$.

One of the key issues in TTS treatment is to determine the presence or absence of left ventricular outflow tract obstruction. The presence of this condition changes the therapeutic approach, including the possibility of using short-acting beta-blockers in patients with cardiogenic shock. ${ }^{19,35}$ The detection of left ventricular outflow tract obstruction is usually made by echocardiography or hemodynamic measures during cardiac catheterization.

\section{Limitations}

The present study has some limitations that need to be considered. First, the study had a short follow-up period (median 354.5 days) and a small number of patients $(n=48)$ compared with international multicenter registries. ${ }^{8}$ This may explain the occurrence of MACE only in the early phase after the diagnosis, as discussed above. Second, not all patients underwent transthoracic echocardiography during the syndrome; 41 (85.4\%) underwent the test, and seven were assessed by other methods three underwent ventriculography during cardiac catheterization and cardiac magnetic resonance; three underwent ventriculography only; and one underwent cardiac magnetic resonance only. ${ }^{36}$ The transthoracic echocardiographic follow-up allows the comparative assessment of ventricular function and of the segments involved, contributing to a better understanding of the syndrome. Also, the test enables the appropriate detection of left ventricular outflow tract obstruction, which is a key point in the TTS treatment. However, despite these limitations, this is the largest registry on the theme conducted in Brazil.

\section{Conclusion}

The present study evidenced the high morbidity and mortality of TTS, diagnosed according to the new InterTAK criteria, in a tertiary center in Brazil, especially during hospitalization and within 90 days after the diagnosis. Based on these findings, further research is urgently needed, mainly to establish the most appropriate therapy for this population.

\section{Author Contributions}

Conception and design of the research: Fundão NHF, Ribeiro HB, Campos CM. Acquisition of data: Fundão NHF, Seleme VB, Soeiro AM, Vieira MLC, Mathias W, Ribeiro EE. Analysis and interpretation of the data: Fundão NHF, Ribeiro HB, Campos CM. Statistical analysis: Campos CM. Writing of the manuscript: Fundão NHF, Ribeiro HB, Campos CM. Critical revision of the manuscript for intellectual content: Hajjar LA, Filho RK.

\section{Potential Conflict of Interest}

No potential conflict of interest relevant to this article was reported.

\section{Sources of Funding}

There were no external funding sources for this study.

\section{Study Association}

This study is not associated with any thesis or dissertation work. 


\begin{tabular}{|c|c|}
\hline & $\begin{array}{c}\text { Without signs } \\
\text { of } \mathrm{HF}^{*}\end{array}$ \\
\hline 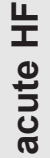 & $\begin{array}{l}\text { ECG monitoring } \\
\geq 48 \text { hours } \\
\text { Consider: } \\
\text { - ACEI or BRAs } \\
\text { - Beta blockers }\end{array}$ \\
\hline है & $\begin{array}{l}\text { * Avoid inotropic } \\
\text { therapy: } \\
\text { - adrenaline } \\
\text { - noradrenaline } \\
\text { - dobutamine } \\
\text { - milrinone } \\
\text { - isoproterenol }\end{array}$ \\
\hline
\end{tabular}

HF/ pulmonary edema

Semi-intensive/ICU

consider:

- ACEI or ARBs

- Beta blockers

- Diuretics (in absence of LVOTO)

- Nitroglycerin /sodium nitroprusside (in absence of LVOTO)

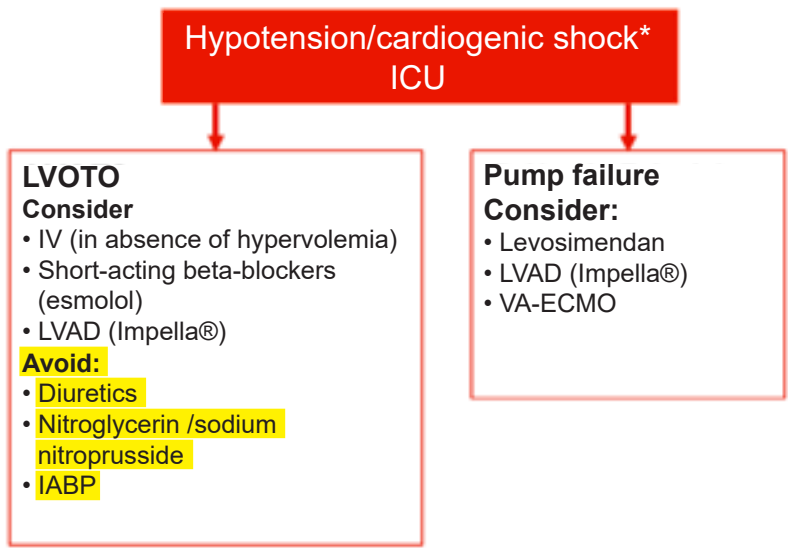

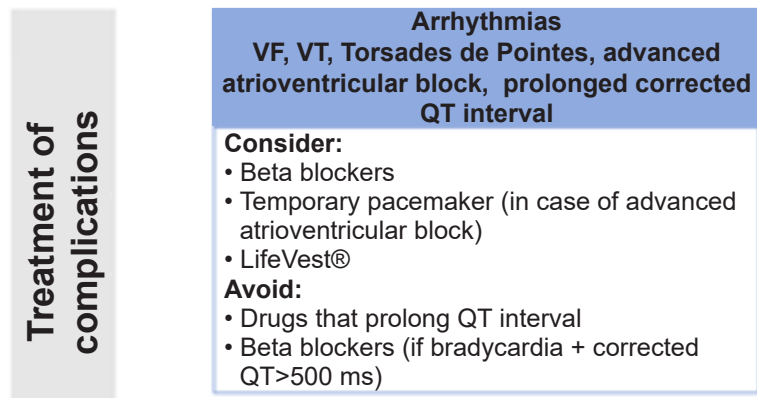

Thrombus/Thromboembolism

LV thrombus, embolization

Heparin/vitamin K antagonist/DOAC

Consider anticoagulation:

- If LVEF $\leq 30 \%$ and/or important left ventricular dysfunction involving the apex

Figure 5 - Current treatment options in Takotsubo syndrome

ACEI: angiotensin converting enzyme inhibitors; ASA: acetylsalicylic acid; AV: atrioventricular; IABP: intra-aortic balloon pump; ARBs: angiotensin II receptor blockers; DOAC: Direct Oral Anticoagulant; ECG: Electrocardiogram; ICU: intensive care unit; LVEF: left ventricular ejection fraction; LVOTO: left ventricular outflow tract obstruction; VF: ventricular fibrillation; IV: intravenous therapy; HF: heart failure; LVOTO: Left Ventricular Outflow Tract Obstruction; LVAD: Left Ventricular Assist Device; VT: ventricular tachycardia; VA-ECMO: venoarterial extracorporeal membrane oxygenation

Modified and adapted from Ghadri et al.(19)

\section{Ethics Approval and Consent to Participate}

This study was approved by the Ethics Committee of the Hospital das Clínicas da Faculdade de Medicina da Universidade de São Paulo - USP under the protocol number 3.279.964. All procedures in this study were in accordance with the Helsinki Declaration of 1975, updated in 2013. No consent form was obtained from the study participants, as it was a retrospective study, only with the collection of secondary data obtained from the analysis of material already collected and review of medical records and without new clinical interventions, the ethics committee waived the need to obtain a free and informed consent form. 


\section{References}

1. Ghadri JR, Wittstein IS, Prasad A, Sharkey S, Dote K, Akashi YJ, et al. International expert consensus document on takotsubo syndrome (Part I): clinical characteristics, diagnostic criteria, and pathophysiology. Eur Heart J. 2018;39(22):2032-46.

2. Tsuchihashi K, Ueshima K, Uchida T, Oh-mura N, Kimura K, Owa $\mathrm{M}$, et al. Transient left ventricular apical ballooning without coronary artery stenosis: a novel heart syndrome mimicking acute myocardial infarction. Angina Pectoris-Myocardial Infarction Investigations in Japan. J Am Coll Cardiol. 2001;38(1):11-8.

3. Kurisu S, Sato H, Kawagoe T, Ishihara M, Shimatani Y, Nishioka K, et al. Tako-tsubo-like left ventricular dysfunction with ST-segment elevation: a novel cardiac syndrome mimicking acute myocardial infarction. Am Heart J. 2002;143(3):448-55.

4. Otten AM, Ottervanger JP, Symersky T, Suryapranata H, Boer MJ, Maas AHEM. Diagnosis of takotsubo cardiomyopathy is increasing over time in patients presenting as ST-elevation myocardial infarction Neth Heart J. 2016;24(9):520-9.

5. Sharkey SW, Lesser JR, Maron BJ. Cardiology patient page. Takotsubo (stress) cardiomyopathy. Circulation. 2011;124(18):e460-2.

6. Prasad A, Lerman A, Rihal CS. Apical ballooning syndrome (Tako-Tsubo or stress cardiomyopathy): a mimic of acute myocardial infarction. Am Heart J. 2008;155(3):408-17.

7. Kato K, Lyon AR, Ghadri JR, Templin C. Takotsubo syndrome: aetiology, presentation and treatment. Heart. 2017;103(18):1461-9.

8. Templin C, Ghadri JR, Diekmann J, Napp LC, Bataiosu DR, Jaguszewski $\mathrm{M}$, et al. Clinical features and outcomes of Takotsubo (Stress) cardiomyopathy. N Engl J Med. 2015;373(10):929-38.

9. Winchester DE, Ragosta M, Taylor AM. Concurrence of angiographic coronary artery disease in patients with apical ballooning syndrome (tako-tsubo cardiomyopathy). Catheter Cardiovasc Interv. 2008;72(5):612-6

10. Kurisu S, Inoue I, Kawagoe T, Ishihara M, Shimatani Y, Nakama Y, et al. Prevalence of incidental coronary artery disease in tako-tsubo cardiomyopathy. Coron Artery Dis. 2009;20(3):214-8.

11. Castillo Rivera AM, Ruiz-Bailen M, Aguilar LR. Takotsubo cardiomyopathy--a clinical review. Med Sci Monit. 2011;17(6):RA135-47.

12. Zeng JH, Li W, Yao FJ, Liu DH, Li CL, Liu YQ, et al. Myocardial contrast echocardiography in the diagnosis of postoperative takotsubo myocardiopathy: case report and literature review. BMC Cardiovasc Disord. 2019;19(1):9.

13. Itoh H, Miyake Y, Hioki I, Tanaka S, Okabe M. Report of takotsubo cardiomyopathy occurring during cardiopulmonary bypass. J Extra Corpor Technol. 2007;39(2):109-11.

14. Chiariello GA, Bruno P, Colizzi C, Crea F, Massetti M. Takotsubo cardiomyopathy following cardiac surgery. J Card Surg. 2016;31(2):89-95.

15. Blazquez JA, Gonzalez JM, Dalmau MJ, Lopez J. Takotsubo cardiomyopathy after elective mitral valve replacement. Interact Cardiovasc Thorac Surg. 2010;11(1):117-9.

16. Bellomo R, Ronco C, Kellum JA, Mehta RL, Palevsky P, Acute Dialysis Quality Initiative Workgroup. Acute renal failure - definition, outcome measures, animal models, fluid therapy and information technology needs: the Second International Consensus Conference of the Acute Dialysis Quality Initiative (ADQI) Group. Crit Care. 2004;8(4):R204-12.

17. Ionescu A. Subaortic dynamic obstruction: a contributing factor to haemodynamic instability in tako-tsubo syndrome? Eur J Echocardiogr. 2008;9(3):384-5.

18. Kawaji T, Shiomi H, Morimoto T, Tazaki J, Imai M, Saito N, et al. Clinical impact of left ventricular outflow tract obstruction in takotsubo cardiomyopathy. Circ J. 2015;79(4):839-46.
19. Ghadri JR, Wittstein IS, Prasad A, Sharkey S, Dote K, Akashi YJ, et al. International Expert Consensus Document on Takotsubo Syndrome (Part II): diagnostic workup, outcome, and management. Eur Heart J. 2018;39(22):2047-62.

20. Y-Hassan S. Takotsubo syndrome triggered by acute coronary syndrome in a cohort of 20 patients: an often missed diagnosis. Int J Cardiol Res. 2015;2(2):28-33

21. Redfors B, Ramunddal T, Shao Y, Omerovic E. Takotsubo triggered by acute myocardial infarction: a common but overlooked syndrome? J Geriatr Cardiol. 2014;11(2):171-3

22. Napp LC, Ghadri JR, Cammann VL, Bauersachs J, Templin C. Takotsubo cardiomyopathy: completely simple but not so easy. Int J Cardiol. 2015;197:257-9.

23. Gaibazzi N, Ugo F, Vignali L, Zoni A, Reverberi C, Gherli T. Tako-Tsubo cardiomyopathy with coronary artery stenosis: a case-series challenging the original definition. Int J Cardiol. 2009;133(2):205-12.

24. Abe $\mathrm{Y}$, Kondo M. Apical ballooning of the left ventricle: a distinct entity? Heart. 2003;89(9):974-6.

25. Cubero JS, Moral RP. Transient apical ballooning syndrome: a transition towards adulthood. Rev Esp Cardiol. 2004;57(3):194-7.

26. Kawai S, Kitabatake A, Tomoike H, Takotsubo Cardiomyopathy Group Guidelines for diagnosis of takotsubo (ampulla) cardiomyopathy. Circ J. 2007;71(6):990-2.

27. Bybee KA, Kara T, Prasad A, Lerman A, Barsness GW, Wright RS, et al Systematic review: transient left ventricular apical ballooning: a syndrome that mimics ST-segment elevation myocardial infarction. Ann Intern Med. 2004;141(11):858-65

28. Elesber AA, Prasad A, Lennon RJ, Wright RS, Lerman A, Rihal CS. Four-year recurrence rate and prognosis of the apical ballooning syndrome. J Am Coll Cardiol. 2007;50(5):448-52.

29. Tornvall P, Collste O, Ehrenborg E, Jarnbert-Petterson H. A case-control study of risk markers and mortality in Takotsubo stress cardiomyopathy. J Am Coll Cardiol. 2016;67(16):1931-6.

30. Stiermaier T, Eitel C, Desch S, Fuernau G, Schuler G, Thiele H, et al Incidence, determinants and prognostic relevance of cardiogenic shock in patients with Takotsubo cardiomyopathy. Eur Heart J Acute Cardiovasc Care. 2016;5(6):489-96.

31. Lyon AR, Bossone E, Schneider B, Sechtem U, Citro R, Underwood SR, et al . Current state of knowledge on Takotsubo syndrome: a Position Statement from the Taskforce on Takotsubo Syndrome of the Heart Failure Association of the European Society of Cardiology. Eur J Heart Fail. 2016;18(1):8-27.

32. Thygesen K, Alpert JS, Jaffe AS, Chaitman BR, Bax JJ, Morrow DA, et al Fourth universal definition of myocardial infarction (2018). Eur Heart J. 2019;40(3):237-69.

33. Redfors B, Vedad R, Angeras O, Ramunddal T, Petursson P, Haraldsson I et al. Mortality in takotsubo syndrome is similar to mortality in myocardial infarction - a report from the SWEDEHEART registry. Int J Cardiol. 2015 Apr 15;185:282-9.

34. El-Sayed AM, Brinjikji W, Salka S. Demographic and co-morbid predictors of stress (Takotsubo) cardiomyopathy. Am J Cardiol. 2012;110(9):1368-72.

35. Santoro F, Ieva R, Ferraretti A, Fanelli M, Musaico F, Tarantino N, e al. Hemodynamic effects, safety, and feasibility of intravenous esmolol infusion during Takotsubo cardiomyopathy with left ventricular outflow tract obstruction: results from a multicenter registry. Cardiovasc Ther. 2016;34(3):161-6.

36. Cerqueira MD, Weissman NJ, Dilsizian V, Jacobs AK, Kaul S, Laskey WK, et al. Standardized myocardial segmentation and nomenclature for tomographic imaging of the heart. A statement for healthcare professionals from the Cardiac Imaging Committee of the Council on Clinical Cardiology of the American Heart Association. Circulation. 2002;105(4):539-42. 